\title{
Paola Cifarelli, Le traduzioni francesi cinquecentesche delle favole di Lorenzo Valla
}

\section{Dario Cecchetti}

\section{(2) OpenEdition}

1 Journals

\section{Edizione digitale}

URL: https://journals.openedition.org/studifrancesi/37402

DOI: 10.4000/studifrancesi.37402

ISSN: 2421-5856

\section{Editore}

Rosenberg \& Sellier

\section{Edizione cartacea}

Data di pubblicazione: 15 décembre 2004

Paginazione: 591

ISSN: 0039-2944

\section{Notizia bibliografica digitale}

Dario Cecchetti, «Paola Cifarelli, Le traduzioni francesi cinquecentesche delle favole di Lorenzo Valla»,

Studi Francesi [Online], 144 (XLVIII | III) | 2004, online dal 30 novembre 2015, consultato il 08 mai 2021 URL: http://journals.openedition.org/studifrancesi/37402 ; DOI: https://doi.org/10.4000/studifrancesi. 37402

Questo documento è stato generato automaticamente il 8 mai 2021.

\section{(c) (1)}

Studi Francesi è distribuita con Licenza Creative Commons Attribuzione - Non commerciale - Non opere derivate 4.0 Internazionale. 


\title{
Paola Cifarelli, Le traduzioni francesi cinquecentesche delle favole di Lorenzo Valla
}

\author{
Dario Cecchetti
}

\section{NOTIZIA}

PAOLA CIFARELLI, Le traduzioni francesi cinquecentesche delle favole di Lorenzo Valla, in Favola, mito ed altri saggi di letteratura e filologia in onore di Gianni Mombello, «Franco-Italica», 23-24 (2003), pp. 85-110.

1 Sul finire del Quattrocento Guillaume Tardif intraprese la traduzione delle trentatré favole esopiche di Lorenzo Valla. Collegandosi alle precedenti ricerche sulla fortuna di Valla in Francia, Paola Cifarelli, sottolineando come la raccolta valliana di Facetiae morales sia stata spesso usata quale fonte dai favolisti francesi del Cinquecento, «si propone di identificare e analizzare comparativamente le traduzioni e gli adattamenti realizzati in ambito galloromanzo durante il XVI secolo, per evidenziare le linee di forza delle poetiche che sottendono alle diverse realizzazioni ed abbozzare, a partire da questo piccolo corpus di esempi, un quadro d'insieme dei differenti modi di intendere la traduzione nell'ambito della favola». Offrire un repertorio dei favolisti francesi che, durante il Cinquecento, si ispirarono alle Facetiae valliane non è facile, in quanto questi favolisti, a differenza di Tardif, non nominano mai la loro fonte latina. È questa pertanto l'impresa a cui si accinge felicemente P. Cifarelli, stabilendo attraverso riscontri puntuali una tabella sinottica che tiene conto di una lettura contrastiva delle raccolte di favole di Corrozet, di Haudent e dell'anonimo traduttore in prosa del 1547. Di queste traduzioni-rielaborazioni del testo valliano viene fatto un confronto che permette di caratterizzarle, traendo conclusioni «sulle linee di forza che contraddistinguono l'atteggiamento dei favolisti cinquecenteschi in materia di 
trattamento delle fonti, di scelta del mezzo espressivo e di posizione assunta, più o meno esplicitamente, nell'ambito del dibattito sulla traduzione». 